\title{
COVID 19: oportunidade de repensar como o dispositivo escolar configura a relação com o saber
}

\section{COVID 19: an opportunity to rethink how the school apparatus configures the relationship with knowledge}

https://doi.org/10.34112/2317-0972a2021V39n82p141-159

\section{Solledad Vercellino ${ }^{1}$}

Resumo: O fechamento de escolas devido à pandemia COVID 19 permite pensar na questão da situacionalidade da aprendizagem escolar. Situacionalidade que nestes tempos mudou. Apoiarei a conjectura, cuja fonte está em uma série de estudos que tenho realizado nos últimos anos em torno da escola primária de um estado subnacional argentino, de que nesta inédita interrupção da escolarização reside a oportunidade não só de tornar visível a potência desse arranjo histórico que é a escola, mas também de relocalizá-la como operação contingente, como sistema de práticas constituído por manobras que podem ser recriadas, reorientadas. É também interessante fundamentar a questão de saber se as novas condições escolares em que se dá a aprendizagem - a escola com sua nova materialidade e suas formas particulares de ordenar e regular pessoas, tempos, espaços, saberes - promoveriam outras aprendizagens ou outras formas de se relacionar com o saber.

PALAVRAS-CHAVE: Aprendizagem escolar e COVID 19; instituição escolar; relação com o saber.

ABStRAct: The closing of schools due to the pandemic COVID 19 allows us to think about the question of the situationality of school learning. Situationality that has changed in these times. I will support the conjecture, whose source is in a series of studies that I have

1. Universidad Nacional de Río Negro. Centro Interdisciplinario de Estudios sobre Derechos, Inclusión y Sociedad. Río Negro, Argentina. Universidad Nacional del Comahue. Centro Universitario Regional Zona Atlántica. Río Negro, Argentina. 
COVID 19: oportunidade de repensar como o dispositivo escolar configura...

carried out in recent years around the primary school of an Argentine subnational state, that in this unprecedented interruption of schooling lies the opportunity not only to make visible the power of this historical arrangement that it is the school, but also to relocate it as a contingent operation, as a system of practices consisting of maneuvers that can be recreated, reoriented. It is also interesting to substantiate the question of whether the new school conditions in which learning takes place - the school with its new materiality and its particular ways of ordering and regulating people, times, spaces.

KEYWORDS: School learning and COVID 19; school institution; relationship with knowledge.

\section{INTRODUÇÃo}

Quase 1,1 bilhão de estudantes e jovens em todo o mundo foram afetados ao longo de 2020 pelo fechamento de estabelecimentos de ensino devido ao surto COVID-19 (UNESCO 2020). Organizações internacionais alertam para os custos sociais e econômicos e a exacerbação das desigualdades educacionais que a suspensão da frequência escolar tem gerado (UNICEF, 2020; UNESCO, 2020).

Como cientista social e, em particular, pesquisador educacional, essa experiência inédita tem sido uma oportunidade inevitável para repensar velhos e novos problemas educacionais decorrentes das medidas tomadas pelos Estados para enfrentar a emergência sanitária.

Este artigo procura enfocar uma dimensão particular do problema: a questão da situação da aprendizagem escolar. Situação que nestes tempos mudou: do edifício escolar para a casa, da presença da sala de aula para uma presença nova, remota, à distância e mediada por tecnologias mais ou menos sofisticadas. Apoiarei a conjectura de que, nesta inédita interrupção da escolarização, reside a oportunidade não só de tornar visível a potência desse arranjo histórico que é a escola, mas também de relocalizá-la como operação contingente, como sistema de práticas constituído por manobras que podem ser recriadas, reorientadas. É também interessante fundamentar a questão de saber se as novas condições escolares em que se dá a aprendizagem - a escola com sua nova materialidade e suas formas particulares de ordenar e regular pessoas, tempos, espaços, saberes - promoveriam outras aprendizagens ou outras formas de se relacionar com o saber.

A fonte de nossas conjecturas está em uma série de estudos que tenho realizado nos últimos anos em torno da escola primária de um estado subnacional argentino (VERCELLINO, 2013, 2020, 2020a, 2020b). Esses estudos se caracterizam por recorrer 
a múltiplas fontes e técnicas de coleta de dados. Em primeiro lugar, uma exaustiva análise documental de 'textos prescritivos' ${ }^{2}$ para e sobre a escola (FOUCAULT, 1996), tais como leis, normas menores, documentos técnicos produzidos pelos Ministérios da Educação, escritos gerados pelas próprias escolas, a produção científica acadêmica local e internacional divulgada por organizações nacionais e supranacionais pré-pandêmica e por ocasião da pandemia. Da mesma forma, antes da pandemia, os dados foram coletados por meio da observação direta do cotidiano escolar em instituições de ensino fundamental, por meio de estudos de caso. Com os alunos dessas escolas foi implementada a técnica de "balanço do saber" (CHARLOT, 2009), na qual eles são solicitados a rever sua aprendizagem e narrar o que aprenderam, com quem e o que esperam aprender. Nas escolas, um total de 81 narrativas e expressões gráficas foram coletadas.

Neste artigo, vou compartilhar um esquema conceitual e analítico que construí para analisar a situação de aprendizagem, com base no uso de duas categorias: a noção de relação com o conhecimento e a noção de dispositivo. A seguir, apresentarei alguns resultados de uma investigação recente, que dá conta da performatividade do dispositivo escolar pré-pandêmico da relação do aluno com o saber. Finalmente, a partir desse quadro, analisarei como o dispositivo escolar foi reconfigurado em tempos de pandemia.

\section{O CONCEITO DE DISPOSITIVO COMO CATEGORIA PARA PESQUISAR A SITUAÇÃO} EM QUE SE ENCONTRA A RELAÇÃO COM O SABER.

Desde a década de 1990, a investigação educativa tem-se focado naqueles componentes estruturais e estruturantes da escola, ou seja, os elementos invariantes que organizam a experiência escolar. A "caixa preta escolar", como Julia a definiu (2001), foi conceitualizada, de acordo com diferentes tradições, como 'forma' (VINCENT; LAHIRE; THIN, 1994), 'gramática' (TYACK; CUBAN, 2001), 'cultura' (JULIA, 2001; VIÑAO FRAGO, 2008; ECOLANO, 2000), 'dispositivo escolar' (QUERRIEN; VARELA, 1994; VARELA; ÁLVAREZ URÍA, 1991; VARELA, 1992) ou 'dispositivo pedagógico' (LANGER, 2013; GRINBERG; LANGER, 2014). Todas essas categorias concordam em referir-se a uma série de regras e práticas de raízes históricas com a capacidade de regular os comportamentos, pensamentos,

2. Estes textos baseiam-se no futuro de algum nível de oficialidade e referem-se à escola primária comum, seus objetivos, âmbito, modo de organização e funcionamento. 
COVID 19: oportunidade de repensar como o dispositivo escolar configura...

gostos estéticos e trabalho de quem habita a escola e definir o que, para a maioria dos atores sociais, é "uma escola", operando num registro do óbvio e natural.

A leitura em termos de dispositivo, profundamente relacional, permite contabilizar as múltiplas imbricações que se estabelecem entre todos os elementos destacados pelos estudos da gramática ou da cultura escolar, bem como valoriza o caráter estratégico da configuração desses elementos, nas suas resistências à modificação e nas suas transformações.

Analisar um dispositivo supõe advertir, como domínio de referência, elementos com uma materialidade heterogênea: discursos, instalações arquitetônicas, leis e regulamentos; enunciados científicos, propostas filosóficas, morais, técnicas; processos econômicos e sociais, que geram certas condições de possibilidade, certas regras de jogo ou formas de racionalidade que organizam as formas de fazer a escola. Trata-se de estudar uma rede, em que os diferentes elementos que a compõem se tornam relevantes na relação de uns com os outros (DELEUZE, 1973, p. 571).

A natureza heterogênea e relacional dos elementos do dispositivo leva a perceber a condição dinâmica que a análise da experiência escolar deve assumir. Tal dinâmica nos confronta com outra característica da análise do dispositivo: seu caráter estratégico (DELEUZE, 1990; AGAMBEN, 2011). Com isso, quero dizer que analisar o mundo escolar em termos de dispositivo supõe investigar táticas, manobras, ações destinadas a nortear outras ações. Estratégias "cujo objetivo é gerir, governar, controlar e orientar - em um sentido útil - os comportamentos, gestos e pensamentos dos homens" (AGAMBEN, 2011, p. 256).

Estamos especialmente interessados nos efeitos do dispositivo escolar, fundamentalmente aqueles que se referem à relação dos alunos com o saber. $\mathrm{O}$ dispositivo tem a capacidade de criar uma disposição para certos tipos de atos, uma tendência para que algumas coisas simplesmente aconteçam, e aconteçam de uma certa maneira. Trata-se da "performatividade do dispositivo", ou seja, "a capacidade dos dispositivos em (re)configurar os atores e suas práticas e os espaços de negociação e jogo que eles abrem" (BEUSCART; PEERBAYE, 2006, p. 4).

A preocupação com a performatividade do dispositivo nos levou a investigar as convenções normatizadas em torno do saber escolar, sua aprendizagem e os aprendizes que são reiterados nesse sistema de práticas que constitui a escola, bem como a atender à configuração dos alunos, aos gestos e atos que realizam como aprendizes.

Em suas últimas obras, Foucault apontará detalhes sobre os grandes domínios em que operam os sistemas práticos - ou dispositivos, performando-os: "o das 
relações de controle sobre as coisas, o das relações de ação sobre os outros e o das relações consigo mesmo" (FOUCAULT, 1994, p. 17). Como estabeleceremos nos parágrafos seguintes, esses três domínios estão integrados e podem ser analisados a partir da heurística da relação do aluno com o saber.

\section{A RELAÇÃo Do(A) ALUNo(A) COM O SABER}

A aprendizagem escolar, também chamada de aprendizagem formal, tem sido objeto de pesquisas de diferentes disciplinas e de diversos posicionamentos epistemológicos e metodológicos. Entendemos que a noção de 'relação com o saber' tem a capacidade heurística de articular na análise da aprendizagem as relações e as múltiplas influências e sobreposições das dimensões destacadas pelas teorias da aprendizagem escolar, ou seja, esclarecer como acontece a aprendizagem no entrecruzamento de diferentes processos cognitivos e metacognitivos com sua ancoragem sócio-histórica e situacional; analisar o vínculo do sujeito aprendiz com os objetos de aprendizagem; indagar as características epistemológicas dos objetos de aprendizagem e a singularidade do psiquismo de quem aprende (VERCELLINO, 2020a).

A relação com o saber é definida como o conjunto organizado, indissociavelmente social e singular, de relações que um sujeito humano mantém com tudo o que depende da aprendizagem e do saber (CHARLOT, 1997). É "a relação de um sujeito com o mundo, consigo mesmo e com os outros". (CHARLOT, 2008, p. 126). Saber é uma forma de significar e agir sobre o mundo, "não há saber senão dentro de uma certa relação com o mundo - que acaba sendo, ao mesmo tempo e pelo mesmo motivo, uma relação com o saber" (CHARLOT, 2008, p. 103).

Charlot (2008), Beillerot et al. (1998) e Chevallard (1991) ressaltam que é relevante dar conta dos saberes que são oferecidos ao aluno, oferta sempre contingente e historicamente construída, o que implica certa seletividade e organização dos saberes disponíveis, bem como dos processos de transformação desses saberes para que se tornem objetos de aprendizagem. Esses autores perceberão também que a relação com o saber supõe o desenvolvimento de uma diversidade de atividades cognitivas, que variam conforme se trate de aprender saberes objetivados, saberes práticos, ou saberes relacionais, vinculados ao estar com os outros na escola. Por fim, eles perceberão que a gênese e a dinâmica da relação com o saber estão inscritas nas contingências da constituição do sujeito como tal, nos desafios por onde se passa sua hominização. 
COVID 19: oportunidade de repensar como o dispositivo escolar configura...

Acontecimentos que ocorrem no seio das tramas intersubjetivas e intergeracionais nos quais se (re)configura tanto a oferta dos saberes quanto as atividades cognitivas.

\section{O DISPOSITIVO ESCOLAR PRÉ-PANDÊMICO}

Nossa pesquisa (VERCELLINO, 202ob) nos permitiu confirmar que a educação pré-pandêmica é sustentada em quatro arranjos que constituem o núcleo duro do dispositivo escolar, ou seja, constituem uma série de compromissos compartilhados em torno do escolar, sedimentados na história, inquestionáveis, naturalizados, e dos quais derivam estratégias secundárias tendentes a sustentá-los, a (re)operar sobre os efeitos que eles realizam. Vários desses acordos foram suspensos como resultado de medidas de saúde tomadas pelos estados em tempos de pandemia.

Uma primeira operação do dispositivo escolar envolve o recrutamento da população escolar. Assim, identificamos como estratégias dos sistemas educacionais o estabelecimento da frequência escolar obrigatória, a remoção de potenciais barreiras de acesso a ela (daí os preceitos da gratuidade e do laicismo), ou a implementação de medidas de auxílio financeiro - bolsas de estudo, transporte escolar etc.; a implementação de medidas corretivas, punitivas ou dissuasivas para aqueles pais que não cumpram com a exigência de mandar seus filhos para a escola; a malha do território e da população para uma localização racional da rede de escolas e, posteriormente, para o desenvolvimento de políticas educacionais voltadas para as populações que não acessam a escola ou que, acessando-a, não cumprem a ordem de assistir com continuidade e/ou aprender os conteúdos previstos. A criação de um corpo de especialistas tanto em gestão e administração escolar (supervisores, inspetores, diretores, etc.) quanto em conhecimentos escolares (professores de graduação, professores especiais) e, daí, a produção de um campo de trabalho que precisa ser regulamentado. Por fim, a produção de informações sobre a população escolar: estatísticas educacionais, relatórios da burocracia escolar, operações avaliativas. Todas essas estratégias constituem práticas múltiplas que garantem que todos os meninos e meninas, desde mais cedo e por mais tempo, estejam na escola, associando, assim, educação com escolaridade.

O dispositivo escolar também supõe a retirada e o fechamento temporário da infância. Esta estratégia requer, adicionalmente, o estabelecimento de um espaço específico para o afastamento da infância da família e do espaço público, o prédio da escola, em cuja construção se materializam "várias camadas de teoria pedagógica, 
algumas escolas de arquitetura, várias disposições de organismos internacionais" (MAR RODRÍGUEZ, 2009, p. 8). No interior do edifício, o espaço se diferencia e se especializa, não só na configuração material, mas também nos móveis e demais objetos nele dispostos. A diferenciação é feita de acordo com as atividades previstas em cada um (espaços abertos e ao ar livre para recreação, espaços com médias padronizadas e determinados requisitos de conforto para o ensino e aprendizagem; espaços comuns, espaços para a administração da escola, para o refeitório, etc.) e também de acordo com as características de seus usuários, tomando fundamentalmente como critérios as funções que desempenham (lugares para professores, equipe de apoio, gestores, alunos), gênero (práticas de divisão espacial persistem a partir de uma ideia binária), sexo e idade (procuramos ter espaços distintos para adultos e crianças e para os mais novos e mais velhos).

Da mesma forma, a população escolar é compartimentada, agrupada e distribuída sob as fórmulas aritméticas que compõem a seção escolar: o agrupamento de alunos de mesma idade e conhecimentos similares, que agora ficam a cargo de um único docente, em um espaço principal designado (sala de aula), ao longo do ano letivo, e a quem será proposta uma oferta única e comum de atividades.

$\mathrm{O}$ confinamento da infância requer que a proximidade entre as pessoas e sua mobilidade sejam reguladas. A disposição das pessoas e objetos na sala de aula estabelece uma distância ótima entre os corpos e promove a quietude e o sedentarismo (ANTELO, 2007) como condições para a aprendizagem.

Outra operação associada é a subtração ou suspensão da responsabilidade parental no tempo-espaço escolar e a transferência desta para os educadores adultos. Conclui-se que o espaço escolar está sujeito a fortes regulamentações sobre os comportamentos que crianças e adultos podem desenvolver. Regulamentações orientadas por uma função de cuidado, entendida como o esforço para que as crianças estejam sempre na presença e sob o olhar de um adulto, de forma que se garanta sua segurança, ao nível da manutenção física, emocional e social, e a prevenção e antecipação dos danos que a interação em grande número pode gerar.

O dispositivo escolar implica também na produção de um espaço-tempo comum, único e diferenciado de outros tempo-espacialidades contemporâneas da infância. Nele, as atividades escolares são sincronizadas, incluindo ensino e aprendizagem, mas também descanso, alimentação etc. Isso pressupõe a pretensão de combinar sensibilidade e compromisso: todos devem comparecer, relaxar, comer, brincar ao mesmo tempo. Também se estabelece um tempo padronizado e repetitivo, que configura 
COVID 19: oportunidade de repensar como o dispositivo escolar configura...

diretrizes padronizadas de referência tanto para o ensino quanto para a aprendizagem. A análise da cronologia da aprendizagem escolar, sua caracterização como monocromática, ou seja, que segue um ritmo igual para todos, foi repetidamente alertada e analisada por Terigi (2010). Essas diretrizes padronizadas de referência para o ensino e a aprendizagem se articulam e se subordinam a outros motivos de relevância política, higiênica, empresarial e, fundamentalmente, à disponibilidade de recursos humanos e à gestão do trabalho docente: os calendários escolares.

Por fim, o último arranjo que identificamos no dispositivo escolar é a produção de um tipo específico de aprendizagem, a aprendizagem escolar. Isso pressupõe a seleção e classificação (com instrumentos diversos: leis, prescrições curriculares, programas de promoção de determinados conteúdos etc.) do conjunto de enunciados e evidências que constituem o conhecimento de cada época. Em seguida, a transformação do conhecimento em conhecimento para ensinar, o que implica sua textualização, objetificação e autonomização. Assim mesmo, a delimitação de um minimum com ênfase na lectoescritura e cálculo. A isso se soma a organização do ensino e da aprendizagem por disciplinas escolares, que envolve a combinação de uma forma de agrupamento de saberes com a alocação de um tempo fixo e padronizado para determinada aprendizagem, a determinação do recurso humano responsável pelo ensino e de um espaço material para ele (sala de aula, laboratório, sala de artes etc.).

O sequenciamento do conhecimento e o estabelecimento de parâmetros da velocidade assumida para o ensino e aprendizagem se acrescenta às pautas normalizadas de referência de ensino e aprendizagem já desenvolvidas. Com auxílio dessas pautas, podem se corroborar de forma indireta os fenômenos não diretamente comparáveis, como os de aprendizagem singular.

\section{O CARÁTER PERFORMATIVO DA RELAÇÃO COM O SABER}

A pesquisa permitiu perceber como o sistema de práticas e as dinâmicas - analisadas na seção anterior - geraram, nos casos em estudo, convenções e performances em relação à oferta de saber, às atividades cognitivas e às tramas intersubjetivas e intergeracionais em que se (re)configuram.

O sistema de práticas que descrevemos se caracteriza por ser repetitivo e repetível, características que também o tornam inteligível. Ele tem uma história e um significado sedimentados, por isso adquire peso, força e valor suficientes para produzir efeitos. Já a partir de Butler (2002) notamos que o efeito performativo é sustentado em uma 
performance constante, em uma atuação repetível; não se trata de cumprir as convenções que se tornaram normas mais ou menos formais, mas de agir de acordo com elas.

A partir da heurística da relação do aluno com o saber, encontramos evidências de que os arranjos estratégicos que compõem o dispositivo escolar operam na trama relacional em que ocorre a oferta de saberes, não só hierarquizando e transformando o saber, mas também exigindo determinadas atividades cognitivas para sua aquisição e disposição da produção de um si mesmo em relação ao saber escolar. A seguir, vamos desenvolver cada um desses aspectos.

Identificamos que as tramas intersubjetivas, intergeracionais e relacionais da relação com o saber no ambiente escolar se tecem e se sustentam em três configurações de performances, entendidas como um conjunto de convenções que se tornam gestos, ditos e ações de alunos e professores:

a. Configuração de performances de trabalhos escolares: trata-se das performances ligadas aos conteúdos, temas, atividades que são abordadas em cada aula. Elas se produzem como formas repetidas de ação em relação ao ensino e à aprendizagem: a demonstração, a fala, o slogan e a pergunta no caso do professor e a escuta, o olhar, a escrita, a leitura e a resposta por parte do(a) aluno(a).

b. Configuração de performances da civilidade escolar: refere-se aos comportamentos esperados, modelados e específicos dentro do ambiente escolar e de acordo com os seus regulamentos, não necessariamente vinculados ao "conteúdo" escolar. Surge assim a ação docente que visa canalizar comportamentos, pessoas e também objetos (configuração de sala de aula), em consonância com as formas escolares de resolução de conflitos. $\mathrm{O}(\mathrm{a})$ aluno(a), por sua vez, deve cumprir essas normas, agir sobre elas, apropriar-se delas e até zelar pelo seu cumprimento.

c. Configuração de desempenhos da diferença geracional: engloba ações típicas da condição diferencial de ser adulto e criança. Nelas, os primeiros fornecem objetos e bens escolares, são fiadores da segurança, do bem-estar e do cuidado das crianças e produzem opiniões que significam o que a criança faz e é. Estes últimos jogam, atacam-se e procuram agradar ao adulto. No cotidiano da sala de aula, essas ações aparecem juntas, justapostas. Os desempenhos dos trabalhos escolares competem em empenho e intensidade com os desempenhos ligados à "civilidade escolar". Da mesma forma, grande parte das práticas escolares sustentadas por adultos se referem à regulação das performances infantis; elas procuram controlar o que pulsa e o que não cabe (brincadeira, agressividade, 
COVID 19: oportunidade de repensar como o dispositivo escolar configura...

movimento) no trabalho ou na civilidade escolar. Da mesma forma, nas performances ligadas à diferença geracional, produz-se certa economia amorosa que dinamiza as demais configurações das performances, que se expressa na insistência das crianças em oferecer ou negar seu trabalho ao adulto e no seu ajustamento ou não aos regulamentos da escola, numa provocação ao olhar e à palavra do adulto, que não para de emitir opiniões que avaliam o quão agradável foi a produção ou comportamento do(a) aluno(a).

\section{Atividades Cognitivas}

A heurística da relação com o saber de Charlot (2008) enfoca o tipo de atividade que o aluno desenvolve ao aprender, sinalizando que, diante de diferentes objetos, atividades, dispositivos relacionais, "o indivíduo que 'aprende' não faz o mesmo, a aprendizagem não passa pelos mesmos processos” (CHARLOT, 2008, p. 109). A partir das observações em sala de aula e dos balanços de saber, encontramos as atividades cognitivas promovidas pelo sistema de práticas escolares e aquelas a que os(as) alunos(as) atribuem mais relevância.

As práticas ligadas à civilidade escolar e à diferença geracional são áreas que exigem, como figura de aprendizagem, dominar relações em situação: a relação com o semelhante, com o par, com a autoridade, com o adulto e consigo mesmo, enquanto aluno(a), enquanto menino(a). Nessas configurações de performances, aprender significa dominar a relação com os outros em situação. Aprende-se uma certa forma de habitar a escola e seus espaços, de se relacionar com os adultos de uma forma diferente da de seus pares; trata-se de dominar a relação de si consigo mesmo, a relação de si com os outros e a relação consigo mesmo através da relação com os outros e vice-versa.

Charlot (2008), denomina esse processo epistêmico de distanciamento - regulação. $\mathrm{O}$ produto da aprendizagem não pode ser automatizado, desvinculado da relação em situação, porém, todo discurso ético-moral e cívico-político (que permeia fortemente o campo educacional) supõe um esforço para anunciar, a partir de uma postura reflexiva, o saber sobre o domínio relacional na forma de princípios, de regras.

As performances próprias do trabalho escolar tratam principalmente de dominar a atividade de responder a instruções estabelecidas atreladas, fundamentalmente, à lectoescritura e aos cálculos matemáticos. Os(as) alunos(as) parecem dominar de forma pertinente esse tipo de atividade. Ora, neste tipo de atividade, ao ler, ao escrever, ao resolver um cálculo, existe um eu reflexivo, mas, fundamentalmente, 
trata-se de "um eu tomado em situação, um eu que é corpo, percepções, sistema de atos em um mundo correlacionado com seus atos" (CHARLOT, 2008, p. 113).

Charlot (2008) chama a imbricação do eu em situação ao processo epistêmico em que aprender é dominar uma atividade realizada no mundo. E nos alerta sobre o quão complexo é gerar um saber reflexivo sobre essas atividades: "quanto mais a atividade está sujeita a mini variações da situação, mais ela se inscreve no corpo e mais difícil será dar conta dela integralmente na forma de enunciados" (CHARLOT, 2008, p. 113). Em nível escolar, há um esforço por desenvolver um discurso e uma ação pré-estabelecidos sobre como se resolvem os cálculos, como se deve gerar a produção escrita, sendo a forma discursiva e prática privilegiada, como já descrevemos, o slogan. É um discurso e uma ação técnica sobre o saber passos a seguir com um produto pré-estabelecido.

Há uma diminuição na demanda por processos epistêmicos de objetificação-denominação (CHARLOT, 2008), aqueles que constituem, no mesmo movimento, um saber-objeto de e um sujeito consciente de ter se apropriado de tal conhecimento. $\mathrm{O}$ saber aparece então como um existente em si mesmo, em um universo de saberes diferente do mundo da ação, das percepções, das emoções. (CHARLOT, 2008, p. 111-112).

O saber enquanto saber-objeto é o que nas concepções comuns é entendido como conjuntos de conhecimentos. Estes são inventariados, classificados, acumulados, encontram-se nos livros ou nas bases de dados. Nos casos estudados, ora circula em xerox, ora está escrito no quadro (como afirmação ou regra); em um dos grupos apareceu em livro didático (manual escolar), e também é notado nas fotos que decoram as paredes.

Esse impacto das configurações de performances nas demandas das atividades cognitivas, ou seja, na performatividade do dispositivo escolar das figuras de aprendizagem, explica que nos balanços de saber os(as) alunos(as) dão um valor residual à apropriação de objetos de saber. Quando o fazem, se reproduz a forma de enunciação como disciplinas escolares e/ou como temas dentro delas, que respondem às características adquiridas pela aprendizagem e pelo trabalho escolar.

\section{O APARELHO ESCOLAR EM TEMPOS DE PANDEMIA}

A pandemia COVID-19 causou uma crise sem precedentes. No campo da educação, essa emergência levou ao encerramento massivo de atividades presenciais por instituições educacionais em mais de 190 países, a fim de prevenir a propagação do vírus e mitigar seu impacto. 
COVID 19: oportunidade de repensar como o dispositivo escolar configura...

Apesar do fechamento de estabelecimentos de ensino, os países resolveram a continuidade do ciclo escolar, recorrendo a diferentes modalidades de ensino-aprendizagem à distância. A suspensão das aulas presenciais começou, em quase todos os casos, na segunda semana de março de 2020. Ao contrário de outros países latino-americanos que voltaram a dar aulas presenciais a partir de maio, a Argentina manteve o ensino à distância até o final de seu ano escolar.

As respostas produzidas pelos sistemas nacionais de educação à pandemia mostram uma heterogeneidade de iniciativas que dizem respeito ao planejamento e à governança da crise. A Tabela No. 1 resume algumas delas para o caso da Argentina.

Tabela 1: Sistematização das respostas da Argentina à crise causada pela pandemia COVID-19

\section{Iniciativas destinadas a garantir a governança da educação no contexto da crise do COVID-19.}

Incorporação de telefonia, internet e televisão paga como serviços públicos essenciais na competição e congelamento de tarifas

Prorrogação de inscrição para bolsas "PROG.R.ES.AR."

Acordo conjunto com os sindicatos que regulamenta o ensino no contexto da pandemia e estabelece piso e complementação salarial para professores

Extensão do programa "PROG.R.ES.AR” a alunos e escolas privadas

Programa de Assistência Emergencial de Trabalho e Produção. Transferência de renda e redução das contribuições do empregador para instituições de gestão privada.

Avaliação Nacional do Processo de Continuidade Pedagógica

\section{Recursos de aprendizagem}

Plataforma "Continuamos educando": Materiais e recursos educativos para alunos, professores e famílias. Livraria digital. Links para programas educacionais transmitidos na mídia pública

Plataforma do Instituto Nacional de Formação de Professores: Materiais, instruções, cursos e recursos da web para professores

Programação educacional na mídia pública: programas de televisão e rádio com conteúdo curricular

Cursos virtuais para professores de Educação Técnica e Profissional

Produção de livretos para alunos em situação de vulnerabilidade 
Entrega de netbook e tablet

Livraria digital

Plano Federal de Conectividade Juana Manso: Netbooks, Conectividade com a Internet, Plataforma Educacional Federal

Créditos subsidiados a professores para compra de equipamentos de informática

Treinamento virtual de professores para retornar às aulas presenciais

Renovação de cursos gratuitos de formação de professores

Iniciativas vinculadas a ajustes curriculares, pedagógicos e de avaliação

Quadro federal de diretrizes para a contextualização curricular 2020-2021 e a organização do ensino

Critérios de avaliação, credenciamento e promoção

Medidas abrangentes de apoio ao bem-estar destinadas a professores, alunos e suas famílias

Produção de conteúdos relativos aos direitos da criança e do adolescente do programa Seguimos Educando

Ações da Secretaria Nacional da Criança, do Adolescente e da Família (SENAF): Fortalecimento da linha $102^{3}$ e produção de materiais para contenção socioemocional

Campanha nacional de divulgação contra o grooming

Iniciativa de transferências para apoiar a população vulnerável

Reforço extraordinário para o cartão Alimentar (transferência de renda)

Iniciativa voltada para a saúde

Medidas preventivas em estabelecimentos de ensino. Protocolo de prevenção

Orientações às famílias nas práticas de prevenção e cuidado na Plataforma "Continuamos educando"

Fonte: Elaboração própria do SITEAL (2020)

3. A Linha 102 é um serviço gratuito e sigiloso, com atendimento especializado sobre os direitos de meninas, meninos e adolescentes, que podem ser atendidos em situação de ameaça, violação de direitos ou necessidade de orientação. 
COVID 19: oportunidade de repensar como o dispositivo escolar configura...

Como se vê, no caso da Argentina, as medidas tomadas para dar continuidade ao funcionamento da escola nestas condições especiais abordam aspectos muito diversos, mas que tocam o cerne da escolaridade:

a. o recrutamento da população em idade escolar. Problema histórico dos sistemas educacionais, as circunstâncias derivadas da pandemia COVID 19 colocaram mais uma vez na agenda a questão de como remover potenciais barreiras ao acesso à educação. As estratégias são conhecidas: implementação de medidas de apoio financeiro e outras transferências de recursos - bolsas de estudo, atendimento a instituições de ensino, entrega de equipamentos de informática, liberação de serviços de telefonia e internet; a produção de informações sobre a população escolar (estatísticas educacionais, relatórios da burocracia escolar, pesquisas); ações voltadas para recursos humanos: adequação dos regimes de trabalho docente, facilitação de empréstimos de equipamentos, desenvolvimento de treinamentos, bem como recursos didáticos para professores;

b. a ampliação do espaço-tempo escolar: fechado o espaço material, a escola surge sustentada em uma nova espacialidade, com o desenvolvimento de diferentes recursos e suportes educacionais: plataformas, programas de TV e rádio, cartilhas; a operação de diferenciar o espaço público do familiar é uma das operações suspensas. Dussell (2020) se referirá ao processo de domicialização da escola e suas derivações.

c. ajustes espaço-temporais: ajustes nos calendários acadêmicos, possibilitando a diacronia nos tempos de ensino, organização de protocolos que ordenam a distância entre as pessoas nos espaços escolares com vistas ao retorno à presença;

d. operações sobre o conhecimento a ser ensinado: foram feitas recomendações sobre a priorização ou priorização do conhecimento a ser ensinado e foram tomadas definições sobre o tempo de aprendizagem, com ajustes nos processos de avaliação e acreditação.

CONCLUSÃo: COVID 19 - UMA OPORTUNIDADE PARA REPENSAR COMO O DISPOSITIVO ESCOLAR REALIZA A RELAÇÃO COM O CONHECIMENTO

A escola, este aparelho singular desenhado pelo Ocidente - que se impôs a todo o globo no final do século XIX, harmonizando a educação com a escolarização 
- teve que, em poucas semanas, modificar radicalmente as suas formas, prescindir da sua materialidade e de sua rígida organização temporal.

O fechamento prolongado das escolas implica a interrupção da maior parte daquelas práticas habituais que constituíam diretrizes que permitiam aos atores escolares, professores e alunos, cumprir a sua tarefa previsivelmente.

A suspensão da obrigação de frequentar as escolas também impactou o conjunto de teorias, ideias, princípios, normas, rituais, inércias, hábitos que regula comportamentos, pensamentos, gostos estéticos e o trabalho de quem habita a escola e define o que, para a maioria dos atores sociais, é "uma escola", operando em um registro do óbvio e natural.

Ou seja, assistimos a uma dupla interrupção: no campo do fazer, mas também no campo do sentido, do corpus de sentidos. Não é estranho, então, que a perplexidade nos habite, que a angústia irrompa. Os quadros de referência estáveis, óbvios, naturalizados, não nos servem, não funcionam.

Nesse contexto, a pandemia e as medidas estatais dela derivadas exacerbaram mais uma vez antigos problemas que vinculam a inclusão educacional à justiça social ${ }^{4}$.

A forte interação entre as condições políticas, econômicas, higiênicas e as formas escolares, particularmente sua organização temporal, estiveram em evidência. O contrato inicial e tácito entre ciclos econômicos, organização política e social e escola foi exposto. A escola tem mostrado o papel que desempenha em nossas sociedades como instituição de atendimento a crianças e adolescentes. Nesse sentido, também ficou evidente como a pesquisa educacional e a teoria pedagógica devem a estruturas explicativas que explicam o vínculo substancial entre cuidar e educar.

Mas velhos problemas reaparecem. $\mathrm{O}$ recrutamento da população escolar é reintegrado como um problema, pois as instituições devem garantir o acesso de todos à educação à distância. As estratégias nessa direção também são as usuais: a) repasse de recursos às famílias (bolsas, acesso à conectividade, entrega de $\mathrm{PC}$, material didático); b) (re)reconversão do corpo de especialistas responsáveis pela educação (na sua formação e recrutamento); c) produção de informações (censos e estatísticas educacionais).

4. Da mesma forma, nestes meses, os processos de fragmentação educacional, descentralização e comercialização da educação que já existem se aprofundaram. A escola, com sua pesada materialidade, resistiu, valeu-se (ao menos a escola pública argentina) ao avanço do capitalismo do século XXI caracterizado por ciclos de expansão baseados na satisfação da demanda. Hoje não são poucos os pesquisadores que alertam para o fato de que a educação se tornou uma oportunidade de negócios em escala global e a pandemia em um grande experimento em educação virtual muito bem utilizado por start-ups. Sobre este particular, recomendo a leitura de Dussel (2020), Williamson, Enyon e Potter (2020) e Zimmerman (2020). 
COVID 19: oportunidade de repensar como o dispositivo escolar configura...

Mas a pandemia também trouxe outros problemas novos e sem precedentes. Problemas que estão ligados à natureza performativa do dispositivo escolar. Com o fechamento dos prédios escolares, esses espaços específicos para o afastamento da infância da família e do espaço público, as experiências de subjetivação de crianças e jovens são limitadas.

Por exemplo, a escola ensina a renunciar ao ritmo, à intensidade e à cadência do tempo individual, que é colocado ao serviço da aprendizagem, para a construção de uma temporalidade comum: duas horas para a matemática, uma para as ciências, dez minutos de recreio, meia hora para o almoço; o tempo escolar é mais ou menos uniforme. Hoje reina o tempo individual, o de cada um, um tempo endogâmico, que cada família pode organizar. Soma-se a irrupção da ilusão de um tempo sem interrupção facilitado pelas novas tecnologias: aprender o tempo todo, em qualquer lugar.

As instituições educacionais também oferecem formas específicas de interação social. O que acontecerá com as gerações futuras se estivermos diante do fim do corpo discente, como previsto por Agamben (2020)? Que formas de socialização com membros não familiares são deixadas para as novas gerações? Como se (re) configuram as performances de civilidade e trabalho escolar?

Por fim, urge analisar as transformações que ocorrem nos saberes quando o conhecimento passa a ser ensinado à distância, no seu sequenciamento e no estabelecimento dos parâmetros da velocidade assumida para o seu ensino e aprendizagem (o problema da avaliação), assim como têm mudado todas as oportunidades de aprendizagem que só as performances escolares oferecem, ou seja, aqueles atos e gestos que se repetem desde tempos imemoriais na escola, que nos constituem como professores e alunos.

\section{REFERÊNCIAS}

AGAMBEN, G. ¿Qué es un dispositivo? Sociológica México, Ciudad de Mexico, 26 (73), 249-264, 2011. AGAMBEN, G. Requiem por los estudiantes. Blog Artillería Inmanente, 23/05/2020. Disponível em: https://artilleriainmanente.noblogs.org/?p=1514. 2020. Acesso em: 7/8/2020.

ANTELO, E. Variaciones sobre el espacio escolar. Las formas de lo escolar. Buenos Aires: Estante Editorial. (p. 59-78), 2007. (Serie Educación).

BADIOU, A. La aventura de la filosofía francesa a partir de 1960. Buenos Aires: Eterna Cadencia Editora, 2013.

BAQUERO, R. Vigotsky y el aprendizaje escolar. Aique, v. 4, p. 278-287, 1999.

BAQUERO, R. La educabilidad bajo sospecha. Cuadernos de pedagogía, 4 (9), 71-85, 2001. 
BAQUERO, R., DIKER, G. y FRIGERIO, G. (2007) (Comps.). Las formas de lo escolar. Buenos Aires: Del estante editorial, 2001.

BAQUERO, R.; TERIGI, F.; TOSCANO, A. G.; BRISCIOL, B.; SBURLATTI, S. Variaciones del régimen académico en escuelas medias con población vulnerable. Un estudio de casos en el área metropolitana de Buenos Aires: REICE: Revista Electrónica Iberoamericana sobre Calidad, Eficacia y Cambio en Educación, v. 7, n. 4, p. 292-319, 2009.

BAQUERO, R.; TERIGI, F. En búsqueda de una unidad de análisis del aprendizaje escolar. Apuntes pedagógicos, 2, 1-16, 1996.

BEILLEROT, J.; BLANCHARD-LAVILLE, C.; MOSCONI, N. Saber y relación con el saber. Buenos Aires: Paidós Educador, 1998.

BEUSCART, J. S.; PEERBAYE, A. Histoires de dispositifs. Paris: Terrains travaux, (2), 3-15, 2006.

BUTLER, J. Cuerpos que importan. Sobre los límites materiales y discursivos del sexo. Buenos Aires: Paidós, 2002.

CEPAL. La educación en tiempos de la pandemia de COVID-19. Comisión Económica para América Latina y el Caribe (CEPAL) y la Oficina Regional de Educación para América Latina y el Caribe de la Organización de las Naciones Unidas para la Educación, la Ciencia y la Cultura. p. 1-20, 2020.

CHARLOT, B. Educação e Globalização: uma tentativa de colocar ordem no debate. Sísifo. Revista de Ciências da Educação, 4, 129-136, 2007.

CHARLOT, B. Las relaciones con el saber. Elementos para una teoría. Buenos Aires: Libros del Zorzal, 2008a.

CHEVALLARD, Y. La transposición didáctica. Del saber sabio al saber enseñado. Buenos Aires: Aique, 1991.

DELEUZE, G. ¿En qué se reconoce el estructuralismo?. In: CHATELET, F. (Dir.): Historia de la filosofía. Tomo IV. Madrid: Espasa Calpe, 1973. p. 567-599.

DELEUZE, G. ¿Qué es un dispositivo? Michel Foucault, filósofo, 155-163, 1990.

DELEUZE, G. El saber: curso sobre Foucault. Buenos Aires: Editorial Cactus, 2011.

DUSSEL, I. La escuela en la pandemia. Reflexiones sobre lo escolar en tiempos dislocados. Práxis Educativa, v. 15, p. 1-16, 2020. Disponível em: https://revistas.apps.uepg.br/index.php/ praxiseducativa/article/view/16482. Acesso em: 3/10/2020.

FOUCAULT, M. ¿Qué es la ilustración? Ciudad de México: Sociológica México, $7 / 8$ (3) s/p., 1988.

FOUCAULT, M. Historia de la sexualidad 2. El uso de los placeres. Madrid: Siglo Veintiuno Editores, S.A, 1996.

GARCÍA FANLO, L. ¿Qué es un dispositivo? Foucault, Deleuze, Agamben. Parte Rei Revista de Filosofía, 74-11-26, 2011.

GRINBERG, S. M.; LANGER, E. D. Insistir es resistir: Dispositivos pedagógicos y pobreza urbana en tiempos de gerenciamiento. Revista Instituto de Investigaciones en Ciencias de la Educación Revista del IICE, 34. 29-46, 2014. Disponível em: http://hdl.handle.net/11336/34189. Acesso em: 14/o6/2019.

GVIRTZ, S., e LARRONDO, M. Notas sobre la escolarización de la cultura material. Celulares y computadoras en la escuela de hoy. Revista Teias, 8 (14-15), 1-10, 2007. 
COVID 19: oportunidade de repensar como o dispositivo escolar configura...

HARGREAVES, A.; GOODSON, I. Educational change over time? The sustainability and nonsustainability of three decades of secondary school change and continuity. Educational administration quarterly, 42 (1), 3-41, 2006.

JULIA, D. A Cultura Escolar como Objeto Histórico. Revista Brasileira de Historia da Educação, 1 (1 [1]), 9-43, 2012.

LAHIRE, B. THIN, D.; VINCENT, G. (1994). Sur l'histoire et la théorie de la forme scolaire. Vincent, G. L'Education prisonnière de la forme scolaire? Scolarisation et socialisation dans les sociétés industrielles, Presses Universitaires de Lyon, p. 11-48, 2012.

LANGER, E. Los dispositivos pedagógicos en las sociedades de control: prácticas de resistencia de estudiantes y regulación de las conductas en escuelas secundarias en contextos de pobreza urbana del Partido de San Martín, 2013.

MAR RODRÍGUEZ, H. Pedagogía y arquitectura [Editorial]. Educación y Pedagogía, 21 (54), 5-8, 2009. Disponível em: http://aprendeenlinea.udea.edu.co/revistas/index.php/revistaeyp/ article/view/9777/8986. Acesso em: 06/11/2020.

OCDE. Panorama de la educación 2017. Indicadores de la OCDE. Madrid: Fundación Santillana, 2017. QUERRIEN, A.; VARELA, J. Trabajos elementales sobre la escuela primaria. Madrid: La Piqueta, 1994. QUEZADA, R. Latin American National Responses to COVID-19 in Digital Learning: Current Trends and Future Impact 2020.

RAFFNSØE, S.; GUDMAND-HØYER, M. T.; e THANING, M. S. What is a Dispositive? Foucault's Historical Mappings of the Networks of Social Reality. Frederiksberg: Copenhagen Business School [wp], 2014.

SISTEMA DE INFORMACIÓN DE TENDENCIAS EDUCATIVAS EN AMÉRICA LATINA (SITEAL). Sistematización de respuestas de los sistemas educativos de América Latina a la crisis de la COVID-19, 2020 [on-line]. Disponível em: https://www.siteal.iiep.unesco.org/respuestas educativas_covid_19. Acesso em: 01/11/2020.

TERIGI, F. Diez miradas sobre la escuela primaria. Buenos Aires: Siglo XXI, 2006.

TERIGI, F. (2010). Las cronologías del aprendizaje: un concepto para pensar las trayectorias escolares. Conferencia de la Jornada de Apertura del Ciclo Lectivo 2010. Ministerio de Cultura y Educación, Gobierno de La Pampa. 23 de febrero del 2010. Disponível em: https://cfvila.com.br/image/catalog/ pdf/2018/Viagens/Tx.\%20Cronologias\%2ode\%20Aprendizagem..pdf. Acesso em: 10/11/2020.

TYACK, D.; CUBAN, L. En Busca de la Utopía: un siglo de reformas en las escuelas públicas. México: Fondo de Cultura, 2001.

UNICEF Argentina (2020). Encuesta Covid-19. Percepciones y actitudes de la población. Impacto de la pandemia en hogares con niños, niñas y adolescentes. Mayo 2020. Informe Sectorial Educación. Disponível em: https://www.unicef.org/argentina/media/8056/file/Covid19EncuestaRapidaInformeEducacion.pdf. Acesso em: 10/11/2020.

VARELA, J. Categorías espacio temporal y social acción escolar: del individualismo al narcisismo. Revista-de-Educación, (298), 7-29, 1992.

VARELA, J.; ALVAREZ-URIA, F. Arqueología de la Escuela. Madrid: Las ediciones de la piqueta, 1991. VELEDA, C. Nuevos tiempos para la educación primaria: Nuevos tiempos para la educación primaria. Lecciones sobre la extensión de la jornada escolar. UNICEF Argentina, 2013. 
VERCELLINO, S. La (re) organización del dispositivo escolar en escuelas primarias que implementan un programa de extensión de la jornada escolar. Propuesta educativa, (39), 92-94, 2013 a.

VERCELLINO, S. (2020). Sobre el dispositivo y su potencia para pensar lo escolar. In: ACOSTA, F.: Derecho a la educación y escolarización en América Latina. Los Polvorines: Universidad Nacional de General Sarmiento, 2020. Disponível em: https://rid.unrn.edu.ar/bitstre $\mathrm{am} / 20.500 .12049 / 5430 / 3 / 9789876304801-c o m p l e t o \% 283 \% 29-97-118 . p d f$. Acesso em: 15/11/2020.

VERCELLINO, S. Usos de la noción de relación con el saber en la investigación educativa y psicopedagógica. Educação (UFSM), 45, 107-1, 2020.

VERCELLINO, S. La performatividad del dispositivo escolar de la relación del-la alumno-a con el saber (Doctoral dissertation), $202 \mathrm{ob}$.

VERCELLINO, S. Educación inclusiva y condiciones de escolarización: aportes para pensar el aparato escolar en tiempos de pandemia. I Simposio Latinoamericano y Caribeño en investigación sobre educación inclusiva. Centro de Estudios Latinoamericanos de Educación Inclusiva (CELEI) de Chile, en colaboración con la Corporación Universitaria Iberoamericana, de Bogotá, Colombia. 24 de Septiembre 2020. Disponível em: https://rid.unrn.edu.ar/bitstream/20.500.12049/6030/1/ CELEI_2020\%20\%281\%29.pdf. Acesso em: 20/11/2020.

VIÑAO FRAGO, A. Escolarización, edificios y espacios escolares. CEE Participación Educativa, 7, 16-27, 2008.

WILLIAMSON, B.; ENYON, R.; POTTER, J. Pandemic politics, pedagogies and practices: digital technologies and distance education during the coronavirus emergency. Learning, Media and Technology, v. 45, n. 2, p. 107-114, 2020.

ZIMMERMAN, J. (2020). Coronavirus and the Great Online-Learning Experiment. Chronicle of Higher Education, 10 de março de 2020.

\section{SOBRE A AUTORA}

Solledad Vercellino. Professora pesquisadora da Universidade Nacional do Rio Negro e Universidade Nacional de Comahue, Argentina.

E-mail: svercellino@unrn.edu.ar.

Recebido em 17 de fevereiro de 2021 e aceito em 14 de julho de 2021. 